Pesquisa e Reflexão em Educação Básica

\title{
Juventudes e o mundo do trabalho: expectativas e anseios dos estudantes do Ensino Médio Integrado do Instituto Federal de Educação Ciência e Tecnologia
}

Marinez Mauer ${ }^{1}$

Luciana Michele Martins Alves ${ }^{2}$ Rita Cristine Basso Soares Severo ${ }^{3}$

\begin{abstract}
Resumo:
O presente artigo tem como objetivo discutir com os jovens estudantes do Ensino Médio Integrado do Instituto Federal de Educação, Ciência e Tecnologia do Rio Grande do Sul sobre seus anseios e suas expectativas em relação ao mundo do trabalho. Este trabalho se fundamenta na pesquisa qualitativa, com dados construídos a partir de rodas de conversas, entrevistas e observações participantes. $O$ referencial teórico aborda o campo das juventudes, bem como do Ensino Médio Integrado. O eixo analítico que apresentamos trata sobre a moratória social que, na perspectiva de Margulis e Urresti, caracteriza-se por um tempo a mais que os jovens de classe média e alta têm para viver sua condição juvenil e concluir seus estudos sem uma preocupação demasiada com o mundo do trabalho. Assim, foi considerado que os sujeitos da pesquisa vivenciam a moratória social e a compreendem como um privilégio e como uma oportunidade de continuarem sua formação acadêmica projetando sua inserção no mundo do trabalho após a saída do Ensino Superior.
\end{abstract}

\author{
Palavras-chave: \\ Educação Profissional. Juventudes. Mundo do Trabalho.
}

\section{Youths and the world of work: expectations and desires of the students of Integrated High School from Instituto Federal de Educação Ciência e Tecnologia}

\begin{abstract}
This article aims to discuss with young students of Integrated High School of Federal Institution of Education, Science and Technology of Rio Grande do Sul about their yearnings and expectations in relation to the world of work. This paperwork is based on qualitative research, with constructed data from conversation circles, interviews and participant observations. The theoretical reference approaches
\end{abstract}

1 Mestre em Educação Profissional. E-mail: mmarinezmauer@gmail.com. ORCID iD: http://orcid.org/0000-0002-0584-6617. 2 Mestre em Educação Profissional. E-mail: lucianamichelen@yahoo.com.br. ORCID iD: http://orcid.org/0000-0001-5664-775X. 3 Doutora em Educação, Professora Adjunta do Curso de Pedagogia na Universidade Estadual do Rio Grande do Sul (UERGS). Professora do Programa de Pós-Graduação em Educação da Universidade Estadual do Rio Grande do Sul (PPG/UERGS). E-mail: rita-severo@uergs.edu.br. ORCID iD: http://orcid.org/0000-0003-4889-7569. 
the youth field, and also the Integrated High School. The analytical axis that we present deals with the social moratorium that is characterized, from the perspective of Margulis and Urresti, by a longer time that young people of middle class and high class have to live their youthful condition and complete their studies without an exceeding concern with the world of work. Thereby it was considered that the students experience the social moratorium and understand as a privilege and as an opportunity to continue their studies and planning their entrance in the world of work after leaving academic education.

Keywords: Professional Education. Youth. World of Work.

\title{
Juventudes y el mundo del trabajo: expectativas y deseos de los alumnos del Bachillerato Integrado del Instituto Federal de Educação Ciência e Tecnologia
}

\begin{abstract}
Resumen: Este artículo tiene como objetivo debatir con los jóvenes estudiantes de Escuela Secundaria Integrada del Instituto Federal de Education, Ciência y Tecnología del Rio Grande do Sul sobre sus anhelos y sus expectativas en relación con el mundo laboral. Este trabajo se basa en una investigación cualitativa, con datos construidos a partir de círculos de conversación, entrevistas y observaciones participantes. El referencial teórico aborda el campo de la juventud y también la escuela. El eje analítico que presentamos trata de la moratoria social que se caracteriza, desde la perspectiva de Margulis y Urresti, por un mayor tiempo que tienen los jóvenes de clase media y alta para vivir su condición de juventud y terminar sus estudios sin preocuparse demasiado con el mundo de trabajo. Se consideró que los estudiantes viven la moratoria social y entienden como un privilegio y como una oportunidad para continuar su formación académica proyectando su inserción en el mundo laboral luego de dejar la Educación Superior.
\end{abstract}

Palabras clave: Educación Profesional. Juventud. Mundo Laboral.

\section{Introdução}

Este artigo foi produzido a partir de uma dissertação de Mestrado Profissional em Educação, realizado na Universidade Estadual do Rio Grande do Sul (UERGS), intitulada Juventudes e o mundo do trabalho: Instituto Federal Campus Osório como espaço de formação. A pesquisa realizada teve o intuito de criar espaços de fala aos jovens estudantes do Ensino Médio Integrado sobre seus anseios e expectativas em relação ao mundo do trabalho, mundo esse que se apresenta de forma volátil, fragmentada e flexibilizada pelas novas estruturas de trabalho do mundo contemporâneo.

Apresenta-se aqui uma das temáticas abordadas na dissertação: "as relações dos jovens estudantes e o mundo do trabalho". Buscando inspirações no Campo dos Estudos Culturais, articulou-se o estudo com autores como, Dayrell (2014), Margulis e Urresti (2000), Novaes (2006) e Pais (2006), entre outros que abordam o conceito de juventudes no plural, por entenderem que não existe apenas uma única categoria de juventude, mas sim, várias formas e possibilidades de ser jovem. Para tecer as considerações sobre os anseios e as expectativas das juventudes em relação ao mundo do trabalho, articulou-se os autores Azevedo e Reis (2014), Leão e Nonato (2014), Morais e Henrique (2017), Pacheco (2010),

Estruturamos esta escrita apresentando inicialmente algumas discussões teóricas que deram suporte para a construção dos procedimentos metodológicos que conduziram a íntegra do estudo apresentado na dissertação, para a dimensão deste texto apresentamos as rodas de conversas que foram metodologicamente conduzindo-nos ao eixo analítico sobre a moratória social discutidos ao final do artigo. 


\section{Referencial teórico}

As juventudes, como nos afirmam Carrano e Dayrell (2014, p. 110), é uma categoria socialmente produzida, destacam, ainda, que:

Temos que levar em conta que as representações sobre a juventude, os sentidos que se atribuem a fase da vida, a posição social dos jovens e o tratamento que lhes é dado pela sociedade ganham contornos particulares em contextos históricos, sociais e culturais distintos.

Compreende-se, assim, que não podemos nos restringir apenas à categoria cronológica, pois desta forma desconsidera-se toda a complexidade que envolve a realidade dos jovens, como as relações de gênero, raça, etnia e as condições econômicas e sociais que constroem suas identidades. Margulis e Urresti (2000) corroboram ao destacar que as juventudes, apesar de estarem vinculadas à idade, são constituídas culturalmente.

Ser jovem, portanto, não depende apenas da idade como uma característica biológica, como uma condição do corpo. Tampouco depende apenas do setor social ao qual se pertence, com a consequente possibilidade de acessar diferentemente uma moratória, uma condição de privilégio. $\mathrm{O}$ fato geracional também deve ser considerado: a circunstância cultural que emana de ser socializada com códigos diferentes, de incorporar novas maneiras de perceber e apreciar, de ser competente em novos hábitos e habilidades, elementos que distanciam os recém-chegados do mundo de gerações mais velhas. (MARGULIS; URRESTI, 2000, p. 04, tradução nossa).

Na mesma direção, Carrano e Dayrell (2014) afirmam que as juventudes são apresentadas como uma categoria que se destacam socialmente, sendo resultado das mudanças na família ao longo das décadas, bem como do trabalho remunerado, e ainda da inserção das crianças e jovens nas escolas. Esses fatores contribuíram para a concepção de juventudes como sendo um estado social que vai além de parâmetros de idade ou biológicos. A partir destes estudos compreende-se que não é possível conceber juventude no singular, pois as características dos contextos diferenciam os jovens entre si, caracterizando juventudes distintas, portanto usamos o termo no plural, para destacar as singularidades. Uma destas singularidades, vivenciada por alguns jovens de determinados contextos, é a moratória social.

Margulis e Urresti (2000) apresentam a moratória social como uma vantagem dos jovens de classe alta, caracterizada por um tempo a mais que o jovem tem para viver experiências sem uma preocupação constante com o mundo do trabalho. Entretanto, é possível perceber diferenças entre os grupos de diferentes classes sociais, enquanto os jovens de classe média e alta possuem este tempo a mais para a formação acadêmica, para jovens de classe baixa, considerados socioeconomicamente vulneráveis, este período é encurtado e a inserção no mundo do trabalho se dá mais cedo, de forma a ter uma renda monetária para ajudar no sustento de suas famílias, ou de si mesmos.

Margulis e Urresti (2000, p. 4-5, tradução nossa), considerando os jovens que têm o privilégio da moratória social, destacam:

a juventude pode ser pensada como um período da vida em que alguém está de posse de um excedente temporário, um crédito ou um adicional, como se fosse algo que foi salvo, algo que é mais do que aquilo que pode estar disponível, que nos jovens é mais reduzido, é gasto, e está terminando mais cedo, irreversivelmente, não importa quanto esforço seja feito para evitá-lo. Desta forma, terá mais probabilidades de ser jovem todo aquele que possui esse capital temporário como condição geral.

A vivência deste tempo estendido também acaba despertando outros desejos nas juventudes, como a necessidade de consumir alguns produtos para manter a sua jovialidade e acompanhar 
culturalmente as tendências da sociedade, gerando um mercado de consumo para as juventudes. Com esse "tempo" estendido, a inserção no mundo do trabalho acaba sendo projetada para o futuro. Cabe aqui diferenciar mundo do trabalho do mercado de trabalho.

O mundo do trabalho diz respeito à complexidade da realidade social, da produção da vida. Nela estão inseridas todas as formas de produção de atividades econômicas (serviço, indústria, comércio, agropecuária), atividades culturais (toda a produção social no âmbito das manifestações da cultura, mídia, cinema, dança, teatro, música, entre outros), enfim, da existência humana. Portanto, o mundo do trabalho abrange a produção de bens e mercadorias, materiais e simbólicas. Assim, uma educação com o foco no mundo do trabalho visa fomentar percursos discentes na direção de uma inserção crítica propositiva e não subordinada ao mercado de trabalho, por meio da formação cidadã e técnica. Isso pressupõe a apropriação dos fundamentos da ciência, da tecnologia, do trabalho e da cultura como etapa imprescindível para o aprofundamento de sua consciência cidadã, possibilitando que atuem criticamente como sujeitos sociais nos contextos em que habitam, técnica e cientificamente munidos para o exercício da cidadania. (AZEVEDO; REIS, 2014, p. 31).

O mundo do trabalho que se apresenta de forma complexa e desafiadora e se não existir um incentivo e amparo, como destacam Leão e Nonato (2014), esse primeiro contato não causa uma boa impressão para as juventudes. Segundo Leão e Nonato (2014) o contexto de desigualdades sociais e desemprego, o trabalho precário e a falta de proteção tem sido o carimbo da inserção das juventudes no mundo do trabalho. Assim, para os autores é preciso pensar o trabalho para os jovens a partir das suas necessidades, "não se pode pensar o trabalho juvenil sem uma rede de proteção social que garanta o atendimento às suas demandas e a preservação de sua integridade física e moral" (LEÃO; NONATO, 2014, p. 23).

Para Ciavatta e Ramos (2011, p. 31) podemos pensar na inserção no mundo do trabalho como educação, pensar no trabalho como um princípio educativo, "isto é, como o fundamento da concepção epistemológica e pedagógica que visa proporcionar aos sujeitos a compreensão do processo histórico de produção científica, tecnológica e cultural". Desta forma, os jovens podem compreender mais sobre as relações sociais estabelecidas neste meio, além dos modos de ser da educação.

Conforme a Lei 11.892/2008 a criação dos Institutos Federais de Educação, Ciência e Tecnologia tiveram como objetivos promover a Educação Profissional Técnica de nível médio de forma integrada, proporcionar cursos em níveis técnicos subsequentes ao Ensino Médio, cursos de Ensino Superior, e ainda, de Pós-graduação. Pacheco (2010, p. 10-11), afirma que o objetivo central dos Institutos Federais "não é formar um profissional para o mercado, mas sim um cidadão para o mundo do trabalho, o qual poderia ser tanto técnico, como filósofo, um escritor ou tudo isso". Significa vencer o prejulgamento de classe de que um trabalhador não possui capacidade de ser um pesquisador, um intelectual ou um artista. Pacheco (2010, p. 24) destaca que "a referência fundamental para a educação profissional e tecnológica é o homem e, por isso, o trabalho, como categoria estruturante do ser social, é seu elemento constituinte". A constituição se dá ao longo da sua vida, através das vivências.

O Instituto Federal foi organizado para atuar em um tripé: ensino, pesquisa e extensão. Assim, são fomentadas a pesquisa e a extensão, com resultados revertidos para a sociedade e para o mundo do trabalho (BRASIL, 2008). A instituição almeja a formação integral dos estudantes e trabalhadores, nas diferentes áreas, bem como o desenvolvimento de respostas em benefício da sociedade, dissipando o conhecimento em conformidade com o mundo do trabalho e as exigências da sociedade, priorizando a sociedade local.

No Ensino Médio Integrado os estudantes terão direito à educação normal, bem como, aos conhecimentos específicos, conforme a escolha do curso. Assim, objetiva-se a unificação da teoria com a prática, preparando o aluno tanto para seguir os estudos quanto para a inserção no mundo do trabalho, tendo como foco a construção humana e cultural (ANDRIONI, 2017). O objetivo maior 
dessa integração é a superação das classes, ou seja, a superação da divisão entre o trabalho manual e intelectual. Assim, não é simplesmente a integração entre ambas, mas construir um Ensino Médio Integrado que integre as estruturas da vida, do trabalho, da ciência e da cultura, construindo novas concepções de vida para as juventudes e contribuindo para superar as divergências de classes.

\section{A construção dos percursos metodológicos}

As juventudes contemporâneas trazem experiências que muitas vezes não são consideradas, não é comum as escolas fazer uma escuta atenta sobre o que os jovens têm a dizer ou a contribuir para a sua própria formação, suas expectativas para o futuro. Estará a escola instrumentalizada para atender os anseios e expectativas dos jovens contemporâneos? Como acontece esta aproximação entre as juventudes e a escola? Qual o papel da escola na formação profissional dos jovens estudantes?

Sabe-se que uma das dimensões que compõem o universo das juventudes contemporâneas são suas relações com o mundo do trabalho. No cenário contemporâneo houve uma fragmentação na estruturação do trabalho, novas tecnologias surgiram novas formas de organização do trabalho que privilegiam as juventudes como sendo a classe trabalhadora ideal, que estaria disposta a inovação. Às flexibilidades impostas pelas mudanças de espaço e tempo do lócus de trabalho e às vulnerabilidades contratuais se fazem cada vez mais presentes na vida destas juventudes.

Nesse sentido, como os jovens contemporâneos encaram estas situações? Quais são as expectativas dos jovens alunos em relação ao mundo do trabalho? Como os alunos percebem as contribuições do Instituto Federal do Rio Grande do Sul Campus Osório em sua formação profissional? Como vivenciam as tensões de ser jovem no mundo do trabalho contemporâneo? Mobilizadas por tais questões os percursos metodológicos foram delineados, pela inserção no Campo dos Estudos Culturais e o campo da Etnografia.

Um estudo etnográfico se apresenta para Geertz (2008) como uma interpretação da cultura do objeto pesquisado, neste caso sujeitos. Segundo Mattos (2011, p. 45), fazer etnografia

[...] é dar voz a uma minoria silenciosa; é caminhar em um mundo desconhecido; é abrir caminhos passando das contingências para a autodeterminação, para inclusão na escola, na vida social, no mundo da existência solidária e cidadã. Fazer etnografia é um pouco de doação de ciência, de dedicação e de alegria, de vigor e de mania, de estudo e de atenção. Fazer etnografia é perceber o mundo estando presente no mundo do outro, que parece não existir mais.

Para realizar esse estudo etnográfico participaram estudantes do IFRS - Campus Osório, situado no Litoral Norte Gaúcho, dos quatro anos do Ensino Médio Integrado, tanto do Técnico em Administração quanto do Técnico em Informática, dos turnos manhã e tarde. Os estudantes tinham entre 15 e 19 anos, totalizando quarenta e três estudantes que participaram das rodas de conversa e entrevistas, e ainda dos registros realizados durante as observações participantes.

Na perspectiva de Mattos (2011) a principal característica da pesquisa etnográfica é a observação participante, pois o pesquisador tem a necessidade de imergir no campo de pesquisa por um vasto período para registrar todos os acontecimentos normais e eventuais dentro da cultura dos sujeitos. Conforme Bogdan e Biklen (1999), no trabalho de campo, o investigador entra no habitat natural do investigado, ambiente, este, em que o sujeito pesquisado realiza as suas tarefas habituais do dia a dia. Neste ambiente, o pesquisador se aproxima do sujeito tornando através do convívio a relação mais natural, assim, o pesquisador estimula os sujeitos a falarem sobre assuntos cotidianos, para incutir que merece a sua confiança, desta forma, construindo uma relação de aproximação. Neste ambiente do sujeito, o pesquisador reúne informações de forma não invasiva tentando aprender algo enquanto participa com o sujeito, mas não de forma competitiva, mas sim com o intuito de aprender com o modo de pensar do sujeito. 
Um dos instrumentos de coleta de dados importante para a pesquisa foram as rodas de conversas baseadas na percepção das autoras Lima e Moura (2014), que acreditam que a roda de conversa é uma forma de produzir informações em que a pesquisadora se insere como elemento da pesquisa contribuindo na conversação e, ainda, propiciando dados para a discussão. Este instrumento proporciona o compartilhamento de experiências e o desdobramento de conceitos sobre o comportamento educativo dos sujeitos. Para as autoras,

As rodas de conversa consistem em um método de participação coletiva de debate acerca de determinada temática em que é possível dialogar com os sujeitos, que se expressam e escutam seus pares e a si mesmos por meio do exercício reflexivo. Um dos seus objetivos é de socializar saberes e implementar a troca de experiências, de conversas, de divulgação e de conhecimentos entre os envolvidos, na perspectiva de construir e reconstruir novos conhecimentos sobre a temática proposta. (MOURA; LIMA, 2014, p. 101).

Para este artigo lançamos mão de depoimentos que fizeram parte de nove rodas de conversas desenvolvidas ao longo da pesquisa. Foram selecionados excertos das conversas que abordaram a temática das expectativas dos estudantes sobre o mundo do trabalho. Os nomes dos estudantes foram preservados, utilizando-se nomes fictícios, apesar das autorizações dos estudantes realizadas pelos termos de consentimento livre e esclarecido.

As rodas de conversas foram realizadas tanto no turno regular de aula destes jovens, como nos intervalos de almoço e no contraturno das aulas. Os estudantes que foram liberados pelos professores para que pudessem participar da roda conversa durante o turno regular de aula, foram estudantes dos quartos anos, pelo fato de já estarem concluindo e terem uma relação de amizade com os professores, que entenderam que este momento de conversa poderia lhes agregar experiências e conhecimentos. Essa colaboração dos professores com os estudantes também se deu por entenderem que o IFRS - Campus Osório é uma instituição que estimula atividades diferenciadas em seu espaço escolar, incentivando os estudantes a participarem de pesquisas e atividades extraclasses.

A formação inicial dos grupos ocorreu de duas formas, uma delas foi por afinidade (em alguns casos convidei grupos de amigos no mesmo momento, então esses grupos se mantiveram), e a outra foi conforme disponibilidade dos estudantes, sempre tentando reunir um grupo de três até sete pessoas, para que a roda de conversa não se tornasse exaustiva, mas também não muito sucinta.

\section{Construções analíticas}

\section{A moratória social como tempo de ampliar a formação acadêmica}

Os jovens estudantes que participaram deste estudo destacaram, ao longo de suas falas, que buscam a qualidade de ensino que a instituição proporciona pensando na preparação para o ingresso no Ensino Superior, antes de ingressarem no mundo do trabalho. São jovens que vislumbram o trabalho para um momento posterior à faculdade, podendo neste momento vivenciar a moratória social, ou seja, viver o tempo da juventude de forma mais leve, usando esse período estendido da juventude para a sua formação.

A maioria dos entrevistados(as) não tem a necessidade de entrar no mercado de trabalho nesse momento, podem viver esse tempo de forma mais leve, se preparando para entrar no mundo do trabalho mais qualificados. Podemos perceber essa afirmação na fala da estudante Roberta.

Eu não penso muito nisso agora porque eu tenho um destino meio que traçado, a ideia é seguir, fazer faculdade, aí eu sei que se eu passar na UFRGS eu não vou trabalhar os meus pais tem condições de me manter então eu sei que eu vou ficar pelo menos uns seis ou sete anos só estudando. (Roberta, 18 anos). 
Outros(as) estudantes também destacaram essa preocupação com a formação acadêmica, entretanto valorizam o curso técnico que estão cursando como forma de ter uma renda durante a faculdade, como afirma Juliano.

Eu sempre fui bem otimista com as oportunidades que eu vou ter quando sair do Instituto Federal, mas eu sempre quis focar mais na minha área acadêmica, posterior fazer uma faculdade e seguir na área de ciências da computação e daí sim trabalhar numa área específica, mas enquanto isso, eu sei que eu vou precisar trabalhar enquanto fizer faculdade, então eu acho extremamente importante eu também ter esse conhecimento, que oportunidade de emprego eu posso ter e realmente o que vou e que eu posso trabalhar saindo como técnico, eu posso trabalhar fazendo site para empresas, posso trabalhar na área, fazer aplicativos, fazer manutenção de computadores, aplicação mais baixo nível, todos os tipos de coisas são abordados. (Juliano, 18 anos).

O jovem estudante Juliano expressou seu desejo de continuar a formação, mas compreende os benefícios dos cursos técnicos a curto prazo. Seguindo nesse pensamento outros(as) estudantes, como o José, eles colocam como prioridade a continuação dos estudos como vemos a seguir:

Eu me sinto um tanto quanto tranquilo, eu vou conforme o tempo sabe, se aparecer a oportunidade eu vou agarrar ela, mas por enquanto não me preocupo com trabalho, assim, mas eu até às vezes me pego pensando se eu vou conseguir trabalhar junto com a faculdade, ou foco só na faculdade ou pego um bicozinho agora no meio de ensino médio, mas eu não me sinto $100 \%$ preocupado com isso por enquanto. (José, 15 anos).

Estes jovens estudantes relatam que a preocupação com o trabalho não é o seu foco, caso tiverem oportunidade irão usufruir, mas, no momento estão mais preocupados com a continuação de sua formação. Percebemos aqui exemplos de jovens vivenciando a moratória social, podendo viver a juventude e os estudos em um primeiro momento, sem trabalhar, junto a isso se preparando para o mundo do trabalho.

Segundo Novaes (2006), o lugar onde o sujeito jovem vive e sua classe social interfere no acesso ao mercado de trabalho, e, muitas vezes, acaba sendo um parâmetro de seleção, podendo tanto favorecer e abrir portas quanto desfavorecer. Os estudantes da pesquisa reconhecem que a escola é o espaço que pode lhes proporcionar condições para buscar o emprego, mas, também entendem que o emprego não está garantido somente pelo fato de estarem estudando, por vezes, a introdução no mundo de trabalho não está ajustada à escolaridade do sujeito.

Os estudantes relatam essas relações conflituosas que se estabelecem no mercado de trabalho, como afirma Ana Júlia (18 anos): "experiência, mas como é que o jovem vai ter experiência se ninguém dá uma chance para ele, então acho que é muito conflituosa desde o início". A falta de incentivo e a exigência por experiência prejudicam a inserção dos jovens no mundo do trabalho. A experiência, como traz Larrosa (2002, p. 21), "é o que nos passa, o que nos acontece, o que nos toca. A cada dia se passam muitas coisas, porém, ao mesmo tempo, quase nada nos acontece." A experiência, é algo que não se adquire sem vivência sem experimentação, no entanto, os estudantes do de Ensino Médio, talvez não tenham vivido tempo suficiente para adquirir experiência em muitas áreas e emerge em suas narrativas a preocupação pela falta de experiência fundamentalmente para ingressar no mundo do trabalho.

A exigência por experiências se modificou ao longo do tempo, porque as formas de trabalho também se transformaram. A estudante Ana Paula destaca:

[...] hoje em dia também se tu quer ter um trabalho bom tá cada vez mais exigente, tipo, por exemplo, eu lembro que meu avô falava que se tinha um curso técnico assim, nossa tu já saía trabalhando e ganhava um monte, hoje em dia tu tem um técnico tu até pode trabalhar, mas eu não recebo tanto. (Ana Paula, 15 anos). 
Apesar de estarem em uma condição de moratória social, as incertezas sobre o mundo do trabalho permeiam as juventudes da instituição. A estudante Maidi (17 anos) afirma: "eu não tenho nenhuma expectativa em relação ao mundo do trabalho, eu só tenho muito receio, dizem que é totalmente diferente do que a gente tem no ensino médio na escola, daí eu fico apavorada”. Outra estudante considera que:

[...] no momento eu só busco um emprego mesmo para início sabe, primeiro emprego com calma, pra depois sei lá fazer um curso para conseguir emprego mais especializado basicamente isso assim, eu sigo caminhando para esse mundo do trabalho e as minhas expectativas não estão muito altas. (Edimara, 18 anos).

Para os autores Leão e Nonato (2014), o trabalho pode se apresentar como uma experiência que marca a vida das juventudes, por envolver diferentes aspectos da vida dos estudantes. Para alguns jovens, que ainda não se encontram no mundo do trabalho, o anseio em trabalhar e a apreensão com o futuro profissional, estão constantemente presentes. Outros que se encontram inseridos no mundo do trabalho, veem no trabalho a viabilidade de estudar, ou ainda, como condição de auxiliar economicamente a família.

Torna-se importante diferenciar o mundo do trabalho, expressão utilizada neste estudo, da expressão mercado de trabalho. Azevedo e Reis (2014) destacam que o mundo do trabalho está relacionado à complexa realidade social que vivemos, relacionado à produção da vida. Assim, este mundo é composto por diferentes atividades econômicas e culturais e abrange a produção de bens, mercadorias, materiais e símbolos. Enquanto mercado de trabalho se designa às relações de oferta e demanda de empregos.

As preocupações dos estudantes com a inserção no mundo do trabalho se apresentam em diferentes estágios. Enquanto alguns já estão trabalhando formalmente, há outros que estão envolvidos com estágios e outros ainda, que estão começando a se preocupar com esta demanda. O estágio é considerado uma pré-inserção no mundo do trabalho, como os estudantes mesmo afirmam: e ainda mais para quem precisa de um auxílio para família, por exemplo, "[...] o estágio é uma ótima opção e tu tem mais um conhecimento para fazer parte, para ter um intuito melhor" (Jocemar, 16 anos).

Entretanto, junto a essa vontade de ter experiências é preciso administrar o tempo. A preparação para a inserção no mundo do trabalho é demonstrada como uma das medidas do Ensino Médio, desta forma, a escola necessita realizar ações educativas que oportunizam ao estudante entender e se encaminhar para o mundo do trabalho contemporâneo, bem como, possibilitar ensaios de formação para o trabalho, se propiciando com projetos de formação técnico-profissional (LEÃO; NONATO, 2014). Ciavatta e Ramos (2011) corroboram com este pensamento de trabalho como educação e afirmam que esta ação possibilita aos estudantes uma inserção nas relações do mundo do trabalho.

Henrique e Morais (2017) destacam que além do trabalho e da formação humana integral, a pesquisa também pode ser um princípio educativo. Conforme as narrativas dos estudantes, os projetos, tanto na área da pesquisa, extensão ou ensino se mostram um diferencial da instituição quando comparada com outras instituições educacionais.

Foi possível perceber que o Instituto Federal, lócus da pesquisa, possibilita aos estudantes diferentes oportunidades de explorarem suas habilidades, seus conhecimentos, além de construírem outros. As jovens estudantes, Gisele e Roberta, destacam as experiências vivenciadas no espaço da escola: "O fato dos projetos, pesquisa e extensão, nossa, isso é demais sabe, isso é um diferencial, quem tem ido para feiras, ver as multiculturas assim" Gisele (18 anos). Roberta (18 anos) corrobora: "Na verdade, a maioria das escolas que não é a nossa nunca teve acesso a esse tripé, ensino, pesquisa e extensão, nem sabe o que é, a gente já se envolveu em projetos". 
Pacheco (2010) destaca que o objetivo dos IFs é "superar o preconceito de classe de que um trabalhador não pode ser um intelectual, um artista", dessa forma, formando cidadãos para o mundo do trabalho e não profissionais para o mercado de trabalho. Para tanto, as novas formas de inserção no mundo do trabalho através do incentivo da arte, da música, do teatro e da literatura precisam estar reunidas no currículo de formação dos estudantes.

\section{Considerações finais}

Prefiro ser

Essa metamorfose ambulante

Eu prefiro ser

Essa metamorfose ambulante

Do que ter aquela velha opinião

Formada sobre tudo

Do que ter aquela velha opinião

Formada sobre tudo...

Raul Seixas, trecho da canção Metamorfose Ambulante

Durante as incursões pela instituição enquanto realizávamos as rodas de conversa éramos expostas a uma metamorfose, como descreve Raul Seixas em sua música. Acompanhávamos os(as) jovens estudantes, e ao perambularmos pelo Campus em busca de novas descobertas buscávamos também nos afastar daquela "opinião formada sobre tudo" sobre os jovens, queríamos nos descolar das representações hegemônicas sobre as juventudes e buscar a construção de espaços de falas reais, conversamos com eles e elas sobre diversos assuntos relacionados à escola, à sua vida estudantil, sobre como estavam os estudos, os anseios e as expectativas em relação ao mundo do trabalho e sobre como vivenciam a sua condição juvenil nos tempos contemporâneos. Os estudantes falavam muito sobre a forma como o ensino é construído nesta escola, como eles como estudantes e seres humanos tiveram que se adaptar e se modificar, passando pela metamorfose, para este novo período no campus e no Ensino Médio.

Ao longo do estudo notou-se que os(as) jovens estudantes que circulam pela instituição valorizam a formação técnica, ao entenderem que ela proporciona oportunidades que o Ensino Médio normal não consegue. Essa visão de mundo dos estudantes é complexa, mas, percebo que os estudantes não se sentem prontos, completos, para ingressarem no mundo do trabalho logo após a conclusão do Ensino Médio. Estas juventudes entendem que precisam ir além, que possuem condições tanto econômicas quanto estruturais para seguir adiante, que são indivíduos capazes de buscar novos horizontes, enfrentar novas barreiras, diferentes obstáculos, com os quais não estão acostumados. Porque durante sua passagem pela instituição aprenderam a buscar e ir além.

Como afirmado anteriormente, a maioria dos estudantes que frequentam a instituição vivenciam a moratória social, apontada por Margulis e Urresti (2000) como um tempo a mais para se dedicar aos estudos, à formação profissional e pessoal e adiar a sua inserção no mundo do trabalho. No entanto, podemos afirmar que esse privilégio é percebido como uma forma de aproveitar as oportunidades que são proporcionadas pela instituição. É importante destacar que essa não é uma condição vivenciada por todas as juventudes, devido às diferenças sociais presentes. Entretanto, os jovens que possuem este privilégio, reconhecem-no e o entendem, pois aproveitam esse tempo para estudar, usufruir das oportunidades da instituição e aprofundar sua formação. 
Foi possível perceber, por meio das narrativas dos estudantes, que os anseios e as expectativas em relação ao mundo do trabalho estão intrinsecamente relacionados às experiências vivenciadas por cada estudante, assim sendo, são relativos e condicionados a cada sujeito de forma independente. A potência dos dilemas que vivenciam sobre estes fatores depende das oportunidades e das experiências já vivenciadas, pois os indivíduos se constituem imbricados na sua cultura.

Os estudantes percebem diferenças entre a instituição de ensino e o mundo do trabalho quando se trata de oportunidades. Enquanto na Instituição se sentem rodeados pelas oportunidades de atividades que lhes são propostas, no mundo do trabalho sentem dificuldades e se deparam com um cenário não tão generoso, mas sim, seletivo e exigente quanto à formação destas juventudes.

Quando um estudo toma como referência a etnografia e inspira-se nos Estudos Culturais, tem como objetivo entender a conduta dos sujeitos participantes a partir de seus pontos de vista, confrontando-os nos espaços que estão imersos, e não apresenta como objeto central a busca por resultados. Desta forma, esse artigo teve o propósito de ouvir as juventudes sobre as temáticas e valorizar estas vozes, expor a potencialidade que elas carregam. Durante a pesquisa foi possível perceber que os sujeitos jovens da pesquisa vêm carregados de significados e experiências, que ao serem consideradas pela instituição se apresentam como uma fonte, uma ferramenta, um instrumento, que pode servir de apoio e amparo à estruturação do currículo da escola. Para os(as) estudantes é muito gratificante poder participar da construção de um currículo que vai contribuir na sua constituição identitária, como estudantes e como cidadãos. Estudos sobre esta temática não se esgotam, porque as juventudes são um campo infinito de informações, em constante transformação, e merecem outros olhares, com outras lentes de outros pesquisadores.

\section{Referências}

ANDRIONI, Ivonei. Educação profissional integrada ao ensino: concepção e categorias fundantes. In: ARAÚJO, Adilson Cesar; SILVA, Cláudio Nei Nascimento da (org.). Ensino médio integrado no Brasil: fundamentos, práticas e desafios. Brasília, DF: Ed. IFB, 2017.

AZEVEDO, José Clóvis de; REIS, Jonas Tarcísio. Democratização do Ensino Médio: a reestruturação curricular no RS. In: AZEVEDO, José Clóvis de; REIS, Jonas Tarcísio (org.). O Ensino Médio e os desafios da experiência. 1. ed. São Paulo: Fundação Santillana: Moderna, 2014.

BOGDAN, Roberto C.; BIKLEN, Sari Knopp. Investigação qualitativa em Educação. Portugal: Porto Editora, 1999.

BRASIL. Lei no 11.892, 29 de dezembro de 2008. Institui a Rede federal de Educação Profissional, Científica e Tecnológica, cria os Institutos Federais de Educação, Ciência e Tecnologia, e dá outras providências. Brasília, DF, dez. 2008. Disponível em: http://www.planalto.gov.br/ccivil_03/_Ato20072010/2008/Lei/L11892.htm. Acesso em: 22 nov. 2018.

CIAVATTA, Maria; RAMOS, Marise. Ensino Médio e Educação Profissional no Brasil: dualidade e fragmentação. Revista Retratos da Escola, Brasília, DF, v. 5, n. 8, p. 27-41, jan./jun. 2011. Disponível em: http//www.esforce.org.br. Acesso em: 13 jun. 2020.

DAYRELL, Juarez; CARRANO, Paulo; Juventude e Ensino Médio: Quem é este aluno que chega à escola. In: DAYRELL, Juarez; CARRANO, Paulo; MAIA, Carla Linhares (org.). Juventude e ensino médio: Diálogos, Sujeitos e Currículos. Belo Horizonte: Editora UFMG, 2014.

GEERTZ, Clifford. A Interpretação das Culturas. Rio de Janeiro: Editora LTC, 2008.

LARROSA, Jorge. Notas sobre a experiência e o saber de experiência. Revista Brasileira de Educação, Rio de Janeiro, n. 19, p. 20-28, jan./abr. 2002.

LEÃO, Geraldo; NONATO, Symaira. Juventude e Trabalho. In: CORREA, Licinia Maria; ALVES, Maria Zenaide; MAIA, Carla Linhares (org.). Cadernos temáticos: juventude brasileira e ensino médio. Belo Horizonte: Editora UFMG, 2014. 
MATTOS, Carmen Lúcia Guimarães de. Estudos etnográficos da educação: uma revisão de tendência no Brasil. In: MATTOS, Carmen Lúcia Guimarães; CASTRO, Paula Almeida de. (org.). Etnografia e educação: conceitos e usos. Campina Grande: EDUEPB, 2011.

MARGULIS, Mario; URRESTI, Marcelo. La juventud es más que una palabra. In: MARGULIS, Mario. La juventud es más que una palabra. Buenos Aires: Editora Biblos, 2000. Disponível em: http://perio.unlp.edu.ar/catedras/system/ files/mario_margulis-la-juventud-es-masque-una-palabra.pdf. Acesso em: 28 nov. 2018.

MORAIS, João Kaio Cavalcante de; HENRIQUE, Ana Lúcia Sarmento. Ensino Médio Integrado: fundamentos e intencionalidade formativa. In: ARAÚJO, Adilson Cesar; SILVA, Cláudio Nei Nascimento da (org.). Ensino Médio integrado no Brasil: fundamentos, práticas e desafios. Brasília, DF: Editora IFB, 2017.

MOURA, Adriana Ferro; LIMA, Maria Glória. A Reinvenção da Roda: Roda de Conversa: um instrumento metodológico possível. In: Revista Temas em Educação, João Pessoa, v. 23, n. 1, p. 98-106, jan./jun. 2014.

NOVAES, Regina. Os jovens de hoje: contextos, diferenças e trajetórias. In: ALMEIDA, Maria Isabel Mendes de; EUGÊNIO, Fernanda (org.). Culturas Jovens: novos mapas do afeto Rio de Janeiro: Editora Jorge Zahar, 2006.

PACHECO, Eliezer Moreira. Os Institutos Federais: uma revolução na educação profissional e Tecnológica. Natal: Editora IFRN, 2010.

PAIS, José Machado. Buscas de si: expressividades e identidades juvenis. In: ALMEIDA, Maria Isabel Mendes; EUGENIO, Fernanda (org.). Culturas Jovens: novos mapas do afeto. Rio de Janeiro: Jorge Zahar Ed., 2006.

SEIXAS, Raul. Metamorfose ambulante. São Paulo: Phillips Records, 1973.

Data de submissão: 31/01/2021

Data de aceite: $22 / 02 / 2021$ 